\title{
Toward a new cold and warm nondepolarizing, normokalemic arrest paradigm for orthotopic heart transplantation
}

\author{
Donna M. Rudd, MSc, and Geoffrey P. Dobson, PhD
}

\begin{abstract}
Objective: Currently, the safe human heart preservation time is limited to around 4 to 5 hours of cold ischemic storage. Longer arrest times can lead to donor heart damage, early graft dysfunction, and chronic rejection. The aim of this study was to examine a new nondepolarizing, normokalemic preservation solution with adenosine and lidocaine for as long as 6 hours of arrest at cold and warmer storage temperatures.
\end{abstract}

Methods: Isolated perfused rat hearts $(\mathrm{n}=87)$ were switched from working to Langendorff (nonworking) mode and arrested at $37^{\circ} \mathrm{C}$ with $200-\mu \mathrm{mol} / \mathrm{L}$ adenosine and $500-\mu \mathrm{mol} / \mathrm{L}$ lidocaine in Krebs-Henseleit buffer (10-mmol/ L glucose, $\mathrm{pH} 7.7,37^{\circ} \mathrm{C}$ ) or with Celsior (Sangstat Medical Corp, Fremont, CA). Hearts were removed and placed in static storage at $4^{\circ} \mathrm{C}$ for 2 and 6 hours or remained on the apparatus and were intermittently flushed at $37^{\circ} \mathrm{C}$ every 20 minutes for 2 minutes at $68 \mathrm{~mm} \mathrm{Hg}$ (average arrest temperature $28^{\circ}-30^{\circ} \mathrm{C}$ ) for 2 and 6 hours. We further investigated the effect of the warmer adenosine-lidocaine solution supplemented with 1 - or $5-\mathrm{mmol} / \mathrm{L}$ pyruvate.

Results: Adenosine-lidocaine solution arrested hearts in $16 \pm 2$ seconds $(n=32)$, whereas Celsior did so in $39 \pm$ 4 seconds $(\mathrm{n}=23)$. After 2 hours of cold static storage, there were no functional differences between the adenosine-lidocaine and Celsior groups, with approximately $70 \%$ return of cardiac output. In contrast, after 6 hours of $4{ }^{\circ} \mathrm{C}$ storage, adenosine-lidocaine hearts had significantly higher functional recoveries $(68 \% \pm 5 \%$ cardiac output) than Celsior hearts ( $47 \% \pm 14 \%$ cardiac output) during 60 minutes of reperfusion. In addition, Celsior hearts took 5 minutes longer to reanimate and showed early reperfusion arrhythmias. At warmer temperatures after 2 hours of arrest, adenosine-lidocaine and Celsior hearts were not significantly different, despite a $43 \%$ higher cardiac output in adenosine-lidocaine hearts $(80 \% \pm 3 \%$ vs $56 \% \pm 12 \%)$. After 6 hours, adenosine-lidocaine hearts had recovered $55 \% \pm 3 \%$ of prearrest cardiac output, which increased significantly to $75 \% \pm 4 \%$ with addition of $1-\mathrm{mmol} / \mathrm{L}$ pyruvate. Adenosine-lidocaine with $1-\mathrm{mmol} / \mathrm{L}$ pyruvate hearts spontaneously recovered $106 \%$ heart rate, $93 \%$ to $105 \%$ developed pressures, $70 \%$ aortic flow, and $81 \%$ coronary flow. Coronary vascular resistance increased 1.7- to 1.9-fold during the 6-hour arrest. In contrast, Celsior hearts did not have return of aortic or coronary flow after 6 hours in these warmer conditions.

Conclusion: A new nondepolarizing, normokalemic adenosine-lidocaine arrest solution in Krebs-Henseleit buffer with $10-\mathrm{mmol} / \mathrm{L}$ glucose was versatile at both $4^{\circ} \mathrm{C}$ and $28^{\circ} \mathrm{C}$ to $30^{\circ} \mathrm{C}$ relative to Celsior, and the addition of $1-\mathrm{mmol} / \mathrm{L}$ pyruvate significantly improved cardiac output at warmer arrest temperatures. This new arrest paradigm may be useful in the harvest, storage, and implantation of donor hearts.

Currently, adult donor heart preservation times from harvest to reanimation are limited to about 4 to 5 hours of cold $\left(2^{\circ} \mathrm{C}-\right.$ $4^{\circ} \mathrm{C}$ ) ischemic storage. ${ }^{1-3}$ Longer arrest times lead to donor heart damage, early graft dysfunction, and possibly chronic rejection. ${ }^{4,5}$ In addition, older hearts are less ischemia tolerant than are younger hearts. ${ }^{6}$ A significant factor leading to donor heart dysfunction and failure is ineffectiveness of current strategies of cardioprotection. A concern during the past decade has been high concentrations of arresting potassium

From the Heart Research Laboratory, Department of Physiology and Pharmacology, James Cook University, Townsville, Queensland, Australia.

Supported in part by the Australian Heart Foundation grant G 05B 2034 (G.P.D.).

Received for publication Feb 23, 2008; revisions received May 21, 2008; accepted for publication June 15, 2008.

Address for reprints: Geoffrey P. Dobson, PhD, Heart Research Laboratory, Department of Physiology and Pharmacology, James Cook University, Townsville,

Queensland, Australia 4811 (E-mail: geoffrey.dobson@jcu.edu.au).

J Thorac Cardiovasc Surg 2009;137:198-207

$0022-5223 / \$ 36.00$

Copyright (c) 2009 by The American Association for Thoracic Surgery

doi:10.1016/j.jtcvs.2008.06.031
(15-125 mmol/L) and the injurious effects of cold-to-warm transition during reperfusion and implantation. ${ }^{7,8}$ Strongly hyperkalemic solutions, such as University Wisconsin solution (125-mmol/L potassium ion), arrest the heart by depolarizing the membrane from $-85 \mathrm{mV}$ to below $-50 \mathrm{mV}$, whereas mildly hyperkalemic solutions, such as Celsior solution (15-mmol/L potassium ion) (Sangstat Medical Corp, Fremont, CA) and St Thomas' Hospital solution No. 2, depolarize the membrane to around $-50 \mathrm{mV} .{ }^{9}$ Depolarizing potassium has no intrinsic cardioprotective properties beyond inducing cardioplegic arrest. High potassium can lead to coronary vasoconstriction and compromise cardioplegia delivery and distribution, ${ }^{10,11}$ damage the vascular endothelium and myocytes, ${ }^{12}$ promote myocardial electrical instability and arrhythmias, ${ }^{13}$ and lead to myocardial stunning. ${ }^{14} \mathrm{~A}$ large part of potassium's untoward effects on the heart is thought to arise from intracellular sodium and calcium ion loading and oxidative stress, which can lead to mitochondrial impairment, necrosis, and apoptosis. ${ }^{15}$ High-potassium solutions may also lead to microcirculatory disturbances, 


\section{Abbreviations and Acronyms \\ $\mathrm{AL}=$ adenosine-lidocaine \\ $\mathrm{CVR}=$ coronary vascular resistance}

such as erythrocyte deformability, observed frequently after restoration of the circulation in transplanted organs. ${ }^{16}$

For more than 10 years, our laboratory has focused on developing a normokalemic nondepolarizing cardioplegia that clamps the membrane potential closer to its resting voltage of $-83 \mathrm{mV}$ by using an adenosine-lidocaine combination (AL) as the active arrest composition. ${ }^{17}$ Our innovation borrows from natural hibernators and places the heart in a more "natural" state of suspended animation. ${ }^{18}$ We have shown that the AL cardioplegia can arrest the heart for as long as 4 hours with $70 \%$ to $80 \%$ recovery of the cardiac output; $85 \%$ to $100 \%$ recovery of heart rate, systolic pressure, and rate-pressure product, and $70 \%$ to $80 \%$ of baseline coronary flows. Only $14 \%$ of hearts arrested with St Thomas' Hospital solution No. 2 survived after 4 hours. ${ }^{17}$ We have also recently demonstrated proof of concept in the canine model of cardiopulmonary bypass. ${ }^{19}$

Our aims in this study were to compare cold AL cardioplegia with $\mathrm{AL}$ at warmer temperatures, to compare $\mathrm{AL}$ with Celsior preservation solution in both states, and to test the effect of adding 1- and 5-mmol/L L-pyruvate to the $\mathrm{AL}$ solution at the warmer arrest temperatures. We found that $\mathrm{AL}$ solution is versatile at both $4^{\circ} \mathrm{C}$ and $28^{\circ} \mathrm{C}$ to $30^{\circ} \mathrm{C}$ and that the addition of 1-mmol/L pyruvate significantly improves cardiac output at warmer arrest temperatures. Celsior solution showed equivalence at 2 hours of arrest but failed to return aortic flow after 6 hours of arrest at $28^{\circ} \mathrm{C}$ to $30^{\circ} \mathrm{C}$. Our new $\mathrm{AL}$ arrest paradigm may find utility in the harvest, ex vivo storage, and implantation of donor hearts at hypothermic to warmer temperatures.

\section{MATERIALS AND METHODS \\ Animals}

Male Sprague-Dawley rats $(350-450 \mathrm{~g}, \mathrm{n}=87)$ were obtained from James Cook University's breeding colony. Animals were fed ad libitum and housed in a 12-hour light/dark cycle. On the day of experiment, rats were anesthetized with an intraperitoneal injection of sodium pentobarbital (Nembutal, $60 \mathrm{mg} / \mathrm{kg}$ body weight), and the hearts were rapidly excised as described in the report of Dobson and Jones. ${ }^{17}$ Rats were handled in compliance with James Cook University Guidelines (ethics approval number A781) and with the Guide for the Care and Use of Laboratory Animals (www.nap.edu/catalog/5140.html). Adenosine (A9251, >99\% purity), sodium L-pyruvate, and all other chemicals were obtained from Sigma Chemical Co (Castle Hill, NSW, Australia). Lidocaine hydrochloride was purchased as a $\%$ solution (ilium) from the local Pharmaceutical Supplies (Lyppard, Queensland, Australia).

\section{Compositions of Buffers and Arrest Solutions}

Krebs-Henseleit perfusion buffer. Hearts were perfused in the Langendorff and working modes with a modified Krebs-Henseleit buffer containing 10-mmol/L glucose, $117 \mathrm{mmol} / \mathrm{L}$ sodium chloride, $5.9-\mathrm{mmol} / \mathrm{L}$ potassium chloride, $25-\mathrm{mmol} / \mathrm{L}$ sodium hydrogen carbonate, $1.2-\mathrm{mmol} / \mathrm{L}$ sodium dihydrogenphosphate, $1.12-\mathrm{mmol} / \mathrm{L}$ calcium chloride $(1.07-\mathrm{mmol} /$ $\mathrm{L}$ free calcium ion), and $0.512-\mathrm{mmol} / \mathrm{L}$ magnesium chloride $(0.5-\mathrm{mmol} / \mathrm{L}$ free magnesium ion), $\mathrm{pH} 7.4$, at $37^{\circ} \mathrm{C}$. The perfusion buffer was filtered with a $1-\mu \mathrm{m}$ membrane and then bubbled vigorously with $95 \%$ oxygen and $5 \%$ carbon dioxide to achieve $\mathrm{P}_{2}$ greater than $600 \mathrm{~mm} \mathrm{Hg}$. The perfusion buffer was not recirculated.

Arrest solutions. The AL solution was made fresh daily and contained $200-\mu \mathrm{mmol} / \mathrm{L}$ adenosine plus $500-\mu \mathrm{mol} / \mathrm{L}$ lidocaine in $10-\mathrm{mmol} / \mathrm{L}$ glucose-containing Krebs-Henseleit buffer $\left(\mathrm{pH} 7.7\right.$ at $\left.37^{\circ} \mathrm{C}\right)$, as described by Dobson and Jones. ${ }^{17}$ The AL arrest solution was filtered with $0.2-\mu \mathrm{m}$ filters and maintained at $37^{\circ} \mathrm{C}$. The arrest solution was not actively bubbled with $95 \%$ oxygen and $5 \%$ carbon dioxide, leading to a higher $\mathrm{pH}$. The average $\mathrm{PO}_{2}$ of the $\mathrm{AL}$ solution was $131 \mathrm{~mm} \mathrm{Hg}$, and the $\mathrm{PCO}_{2}$ was 5 to $10 \mathrm{~mm}$ $\mathrm{Hg}$. The Celsior solution was made fresh daily and contained 100-mmol/L sodium hydroxide, $15-\mathrm{mmol} / \mathrm{L}$ potassium chloride, $13-\mathrm{mmol} / \mathrm{L}$ magnesium chloride, $0.25-\mathrm{mmol} / \mathrm{L}$ calcium chloride, $20-\mathrm{mmol} / \mathrm{L}$ glutamic acid, 80 $\mathrm{mmol} / \mathrm{L}$ lactobionic acid, 30-mmol/L histidine, and 3- $\mathrm{mmmol} / \mathrm{L}$ glutathione (pH 7.3). The solution was filtered with a $0.2-\mu \mathrm{m}$ filter, was not actively bubbled with $95 \%$ and $5 \%$ carbon dioxide, and had an average $\mathrm{Po}_{2}$ of $127.4 \mathrm{~mm} \mathrm{Hg}$

\section{Experimental Groups}

Rats were randomly assigned to 1 of 6 arrest and storage protocols for either 2 or 6 hours: (1) $\mathrm{AL}$ alone for cold $\left(4^{\circ} \mathrm{C}\right)$ static storage $(\mathrm{n}=16)$, (2) $\mathrm{AL}$ alone with warmer $\left(28^{\circ} \mathrm{C}-30^{\circ} \mathrm{C}\right)$ intermittent infusions $(\mathrm{n}=16)$, (3) $\mathrm{AL}$ plus $1-\mathrm{mmol} / \mathrm{L}$ pyruvate with warmer $\left(28^{\circ} \mathrm{C}-30^{\circ} \mathrm{C}\right)$ intermittent infusions $(\mathrm{n}=16)$, (4) $\mathrm{AL}$ plus $5-\mathrm{mmol} / \mathrm{L}$ pyruvate with warmer $28^{\circ} \mathrm{C}-30^{\circ} \mathrm{C}$ intermittent infusions $(\mathrm{n}=16),(5)$ Celsior for cold $\left(4^{\circ} \mathrm{C}\right)$ static storage $(\mathrm{n}=11)$, and $(6)$ Celsior with warmer $\left(28^{\circ} \mathrm{C}-30^{\circ} \mathrm{C}\right)$ intermittent infusions $(n=12)$. Although Celsior is an extracellular-type solution not originally designed for warmer temperatures, the last protocol was included for comparison with AL cardioplegia, because Celsior was designed in part to reduce injury to the heart in the transition from cold to warm reperfusion. ${ }^{20}$

\section{Langendorff and Working Rat Heart Preparations}

Hearts were rapidly removed from anesthetized rats and immediately placed in ice-cold Krebs-Henseleit buffer. Briefly, excess tissue was removed, and the heart was connected by the aorta to a standard Langendorff apparatus and perfused in a retrograde fashion with a perfusion pressure of $90 \mathrm{~cm} \mathrm{H}_{2} \mathrm{O}(68 \mathrm{~mm} \mathrm{Hg})$. After the pulmonary veins and superior and inferior venae cavae were tied off to minimize leaks $(<1 \mathrm{~mL} / \mathrm{min})$, the pulmonary artery was cannulated for collection of coronary venous effluent. A small incision was made in the left atrial appendage, into which another cannula was inserted and tied off for working mode operation. The preparation was then switched to the working mode by switching the supply of perfusate from the aorta to the left atrial cannula at a hydrostatic pressure of $10 \mathrm{~cm}$ $\mathrm{H}_{2} \mathrm{O}$ (preload) and an afterload of $100 \mathrm{~cm} \mathrm{H}_{2} \mathrm{O}(76 \mathrm{~mm} \mathrm{Hg})$. The heart was deliberately not placed in a thermostat-equipped jacket, so that moderate decreases in temperature during arrest would mimic the clinical drift in myocardial temperature. Hearts were stabilized for 15 minutes before conversion back to Langendorff nonworking mode before induction of arrest. Heart rate, aortic pressure, coronary flow, and aortic flow were measured before, during, and after arrest.

Aortic pressure was measured continuously with a pressure transducer (ADI Instruments, Sydney, NSW, Australia) coupled to a MacLab 2e (ADI Instruments). Systolic and diastolic pressures and heart rate were calculated from the pressure trace with the MacLab software. Arterial and venous perfusate $\mathrm{PO}_{2}$ and $\mathrm{PCO}_{2}, \mathrm{pH}$, and ionic (calcium, chloride, and sodium) concentrations were measured with a Bayer 865 blood gas machine (Siemens Australia, Bayswater, Victoria, Australia). Coronary flow and aortic flow were measured in volumetric cylinders. The initial criteria for exclusion of working hearts during the 15-minute equilibration period were 
a heart rate less than 200 beats/min, a systolic pressure less than $100 \mathrm{~mm} \mathrm{Hg}$, and a coronary flow less than $10 \mathrm{~mL} / \mathrm{min}$. Neither pacing nor cardiac massage was used during the reanimation phase in the working mode. The surface temperature of the heart was measured with a Cole-Parmer thermistor-thermometer (8402-20; Cole-Parmer, Vernon Hills, Ill) with the thermistor probe tucked under the left auricle. We previously have shown that placement in the left heart chamber yields similar profiles to subauricular placement. ${ }^{17}$ The perfusion apparatus was flushed weekly with $5 \mathrm{~L}$ of $3 \%$ hydrogen peroxide and $1 \%$ glacial acetic acid solution, followed by a thorough rinse with $10 \mathrm{~L} 18-\mathrm{M} \Omega$ water.

\section{Cold Static Storage $\left(4^{\circ} \mathrm{C}\right)$}

We used the cold static storage method of McDonald and colleagues ${ }^{21}$ with the following modifications. Baseline data were obtained for hearts in working mode at $37^{\circ} \mathrm{C}$. Arrest was induced in the Langendorff mode at normothermia with a 5-minute infusion of cardioplegia solution (50-100 $\mathrm{mL}$ ) through the aorta at a constant pressure of $68 \mathrm{~mm} \mathrm{Hg}$. Hearts were then gently removed from the working heart apparatus, placed in $50-\mathrm{mL}$ tubes containing their respective preservation solutions, and immersed in the water bath set at $4^{\circ} \mathrm{C}$ for 2 or 6 hours. After storage, the hearts were returned to the perfusion apparatus, and fresh arrest solutions were perfused in Langendorff mode. The hearts were slowly rewarmed for 5 minutes before reanimation and reperfusion in working mode for 60 minutes at $37^{\circ} \mathrm{C}$ with oxygenated, glucose-containing Krebs-Henseleit solution at pH 7.4. Functional data (aortic and coronary flows, heart rate, and systolic and diastolic pressures) were measured at predetermined times before arrest and during 60 minutes of reperfusion and compared with the baseline data for each heart.

\section{Intermittent Cardioplegic Delivery at Warmer Arrest Temperatures $\left(\mathbf{2 8}^{\circ} \mathrm{C}-\mathbf{3 0}^{\circ} \mathrm{C}\right)$}

The method of intermittent cardioplegic delivery in the isolated rat heart has been previously described by Dobson and Jones. ${ }^{17}$ Arrest in the Langendorff mode was induced by a 5 -minute infusion of cardioplegic solution $(50-100 \mathrm{~mL})$ through the aorta at $37^{\circ} \mathrm{C}$ and a constant pressure of $68 \mathrm{~mm}$ $\mathrm{Hg}$. After arrest, the aorta was crossclamped at the completion of infusion with a plastic atraumatic aortic clip. Cardioplegia was replenished every 18 minutes with a 2-min infusion, after which the crossclamp was reapplied. After 2 or 6 hours of arrest with intermittent cardioplegic delivery, the heart was switched immediately to the working mode and reperfused with oxygenated, glucose-containing Krebs-Henseleit buffer at $37^{\circ} \mathrm{C}$. The heart temperature during intermittent arrest ranged from $35^{\circ} \mathrm{C}$ during delivery to about $25^{\circ} \mathrm{C}$ before the next delivery (average $28^{\circ}-30^{\circ} \mathrm{C}$ ), as directly measured and discussed by Dobson and Jones. ${ }^{17}$ The working heart was chosen because the ejecting model is more representative of the natural flow through the heart, whereas the standard Langendorff model receives reversal of flow through the aorta and does no physical work.

\section{Determination of Coronary Vascular Resistance During Warmer Intermittent Delivery and of Total Tissue Water}

Coronary vascular resistance (CVR, Mdyne $\left.\cdot \mathrm{s} \cdot \mathrm{cm}^{-5}\right)$ was calculated during each 2-minute cardioplegic delivery by dividing delivery pressure by flow (volume per second) according to the following equation: CVR $=1333 \times$ pressure $($ in $\mathrm{mm} \mathrm{Hg}) \times 10^{-6} /$ flow $($ in $\mathrm{mL} / \mathrm{s})$, where $1 \mathrm{~mm} \mathrm{Hg}$ is equal to $1333 \mathrm{dyne} / \mathrm{cm}^{-2}$ and $10^{-6}$ is a conversion factor from dynes to megadynes.

Total tissue water (as a percentage) was determined by the difference in wet weight and dry weight divided by wet weight and multiplied by $100 \%$. Powdered tissues were obtained from hearts receiving AL, AL with $1-\mathrm{mmol} / \mathrm{L}$ pyruvate, and $\mathrm{AL}$ with $5-\mathrm{mmol} / \mathrm{L}$ pyruvate. After 60 minutes of reperfusion, hearts were dried to a constant weight at $85^{\circ} \mathrm{C}$ for as long as 48 hours.

\section{Statistical Analysis}

All results are expressed as mean \pm SEM. Statistics were performed separately for the 2-hour and 6-hour protocols. One-way analysis of variance was used to compare rats in weight, arrest times, time to first beat, heart rate, developed pressure, rate-pressure product, aortic flow, coronary flow, and cardiac output at separate time points (Table 1 and 2). Twoway analysis of variance with repeated measures was used to compare functional variables during 60 minutes of recovery across multiple time points for the different treatment groups (Figure 1). Significance was then assessed with Bonferroni and Dunnet (2-sided) post hoc tests. The alpha level of significance for all experiments was set at $P<0.05$.

\section{RESULTS}

\section{Arrest Times}

Full normothermic electrochemical arrest in hearts with $\mathrm{AL}$ and no added pyruvate was achieved in $16 \pm 2$ seconds $(\mathrm{n}=32)$, not significantly different from AL with the presence of 1 -mmol pyruvate ( $25 \pm 8$ seconds, $\mathrm{n}=16$ ) or 5 -mmol/L pyruvate $(18 \pm 4$ seconds, $n=16)$. Hearts with Celsior took a longer time to arrest ( $39 \pm 4$ seconds, $n=23$ ); however, this arrest time was not significantly different from the arrest times in the AL groups.

\section{Cold Static Storage $\left(4^{\circ} \mathrm{C}\right)$ : Functional Recoveries After 2 and 6 Hours of Arrest}

The functional data for the AL and Celsior groups undergoing cold immersion storage for 2 and 6 hours are shown in Tables 1 and 2, respectively. After 2 hours, there were no functional differences between the AL and Celsior groups. At 60 minutes of reperfusion in working mode, heart rates were $94 \%$ to $103 \%$ of prearrest values, systolic pressures $92 \%$ to $93 \%$, diastolic pressures $99 \%$ to $106 \%$, rate-pressure products $92 \%$ to $98 \%$, aortic flows $65 \%$ to $70 \%$, coronary flows $82 \%$ to $86 \%$, and cardiac outputs $69 \%$ to $72 \%$ (Table 1).

After 6 hours of cold static storage $\left(4^{\circ} \mathrm{C}\right)$, the hearts in the AL group had spontaneously returned to $105 \%$ of prearrest heart rate, $90 \%$ of prearrest systolic pressure, $105 \%$ of prearrest diastolic pressure, $94 \%$ of prearrest rate-pressure product, $66 \%$ of prearrest aortic flow, $84 \%$ of prearrest coronary flow, and $69 \%$ of prearrest cardiac output (Table 2). In contrast, hearts in the Celsior group had returned to significantly lower functional parameters after 60 minutes of reperfusion according to a 2-way analysis of variance with repeated measures $(P=.006)$. Hearts in the Celsior group had returned to $81 \%$ of prearrest heart rate, $69 \%$ of prearrest systolic pressure, $93 \%$ of prearrest diastolic pressure, $63 \%$ of prearrest rate-pressure product, $41 \%$ of prearrest aortic flow, $47 \%$ of prearrest coronary flow, and $49 \%$ of prearrest cardiac output at 60 minutes reperfusion after 6 hours of static storage arrest (Table 2). Despite the same protocol of reattachment and rewarming of hearts (5 minutes) after cold static storage, hearts in the Celsior group took 5 minutes longer to reanimate in working mode than did those in the AL group (Figure 1,A) and showed early reperfusion 
TABLE 1. Functional parameters: Two-hour arrest protocols

\begin{tabular}{|c|c|c|c|c|c|c|c|c|c|c|c|}
\hline \multirow[b]{2}{*}{ Treatment } & \multirow[b]{2}{*}{$\mathbf{n}$} & \multirow{2}{*}{$\begin{array}{l}\text { Heart rate } \\
\text { (beats/min) }\end{array}$} & \multicolumn{2}{|c|}{ Pressure (mm Hg) } & \multirow{2}{*}{$\begin{array}{c}\text { Rate-pressure } \\
\text { product }(\mathrm{mm} \mathrm{Hg} / \mathrm{min})\end{array}$} & \multicolumn{2}{|c|}{$\begin{array}{c}\text { Aortic } \\
\text { flow }(\mathrm{mL} / \mathrm{min})\end{array}$} & \multicolumn{2}{|c|}{$\begin{array}{c}\text { Coronary } \\
\text { flow }(\mathrm{mL} / \mathrm{min})\end{array}$} & \multicolumn{2}{|c|}{$\begin{array}{c}\text { Cardiac } \\
\text { output }(\mathrm{mL} / \mathrm{min})\end{array}$} \\
\hline & & & Systolic & Diastolic & & Value & $\% \mathbf{P A}$ & Value & $\% \mathbf{P A}$ & Value & $\% \mathbf{P A}$ \\
\hline \multicolumn{12}{|l|}{$15 \mathrm{~min}$ before arrest } \\
\hline $\mathrm{AL}$ cold $\left(4^{\circ} \mathrm{C}\right)$ & 8 & $288 \pm 4$ & $121 \pm 2$ & $60 \pm 1$ & $34,696 \pm 664$ & $62 \pm 1$ & & $21 \pm 1$ & & $83 \pm 2$ & \\
\hline Celsior $\left(4^{\circ} \mathrm{C}\right)$ & 6 & $285 \pm 9$ & $121 \pm 1$ & $60 \pm 0$ & $34,406 \pm 1153$ & $60 \pm 4$ & & $20 \pm 2$ & & $80 \pm 5$ & \\
\hline $\mathrm{AL}\left(29^{\circ} \mathrm{C}\right)$ & 8 & $268 \pm 8$ & $121 \pm 2$ & $60 \pm 0$ & $32,299 \pm 920$ & $48 \pm 2$ & & $16 \pm 1$ & & $64 \pm 2$ & \\
\hline Plus 1-mmol/L Pyr & 8 & $270 \pm 8$ & $121 \pm 1$ & $59 \pm 1$ & $32,688 \pm 738$ & $46 \pm 2$ & & $16 \pm 1$ & & $62 \pm 3$ & \\
\hline Plus 5-mmol/L Pyr & 8 & $274 \pm 9$ & $119 \pm 1$ & $56 \pm 2$ & $32,499 \pm 1098$ & $51 \pm 3$ & & $18 \pm 1$ & & $70 \pm 4$ & \\
\hline Celsior $\left(29^{\circ} \mathrm{C}\right)$ & 6 & $281 \pm 6$ & $123 \pm 2$ & $60 \pm 0$ & $34,397 \pm 682$ & $56 \pm 1$ & & $17 \pm 1$ & & $73 \pm 2$ & \\
\hline \multicolumn{12}{|l|}{$15 \mathrm{~min}$ recovery } \\
\hline AL cold $\left(4^{\circ} \mathrm{C}\right)$ & 8 & $284 \pm 11$ & $113 \pm 4$ & $59 \pm 1$ & $31,944 \pm 979$ & $42 \pm 5$ & $68 \pm 5$ & $15 \pm 1$ & 71 & $56 \pm 6$ & 67 \\
\hline Celsior $\left(4^{\circ} \mathrm{C}\right)$ & 6 & $263 \pm 21$ & $108 \pm 3$ & $63 \pm 2$ & $28,085 \pm 1991$ & $34 \pm 5$ & $57 \pm 9$ & $13 \pm 1$ & 65 & $47 \pm 5$ & 59 \\
\hline $\mathrm{AL}\left(29^{\circ} \mathrm{C}\right)$ & 8 & $238 \pm 8$ & $113 \pm 4$ & $60 \pm 0$ & $26,833 \pm 1312$ & $32 \pm 3$ & $67 \pm 4$ & $15 \pm 1$ & 94 & $47 \pm 3$ & 73 \\
\hline Plus 1-mmol/L Pyr & 8 & $240 \pm 10$ & $116 \pm 2$ & $65 \pm 3$ & $27,874 \pm 959$ & $31 \pm 4$ & $67 \pm 6$ & $16 \pm 1$ & 100 & $46 \pm 3$ & 74 \\
\hline Plus 5-mmol/L Pyr & 8 & $230 \pm 14$ & $115 \pm 3$ & $59 \pm 1$ & $26,223 \pm 1124$ & $28 \pm 3$ & $55 \pm 4$ & $17 \pm 1$ & 94 & $44 \pm 5$ & 63 \\
\hline Celsior $\left(29^{\circ} \mathrm{C}\right)$ & 6 & $203 \pm 45$ & $95 \pm 20$ & $52 \pm 11$ & $23,320 \pm 5424$ & $23 \pm 8$ & $41 \pm 15$ & $14 \pm 3$ & 82 & $38 \pm 10$ & 52 \\
\hline \multicolumn{12}{|l|}{$30 \mathrm{~min}$ recovery } \\
\hline $\mathrm{AL}$ cold $\left(4^{\circ} \mathrm{C}\right)$ & 8 & $293 \pm 14$ & $115 \pm 4$ & $59 \pm 1$ & $33,359 \pm 694$ & $46 \pm 3$ & $74 \pm 3$ & $15 \pm 1$ & 71 & $61 \pm 2$ & 73 \\
\hline Celsior $\left(4^{\circ} \mathrm{C}\right)$ & 6 & $269 \pm 14$ & $113 \pm 3$ & $64 \pm 2$ & $30,228 \pm 1595$ & $40 \pm 3$ & $67 \pm 7$ & $14 \pm 1$ & 70 & $54 \pm 3$ & 68 \\
\hline $\operatorname{AL}\left(29^{\circ} \mathrm{C}\right)$ & 8 & $268 \pm 12$ & $111 \pm 4$ & $60 \pm 0$ & $29,633 \pm 1173$ & $37 \pm 2$ & $77 \pm 3$ & $16 \pm 1$ & 100 & $52 \pm 3$ & 81 \\
\hline Plus 1-mmol/L Pyr & 8 & $265 \pm 9$ & $113 \pm 3$ & $64 \pm 2$ & $29,679 \pm 735$ & $37 \pm 2$ & $80 \pm 3$ & $16 \pm 1$ & 100 & $54 \pm 2$ & 87 \\
\hline Plus 5-mmol/L Pyr & 8 & $249 \pm 7$ & $116 \pm 2$ & $59 \pm 1$ & $28,924 \pm 616$ & $41 \pm 3$ & $80 \pm 2$ & $16 \pm 1$ & 89 & $58 \pm 4$ & 83 \\
\hline Celsior $\left(29^{\circ} \mathrm{C}\right)$ & 6 & $226 \pm 46$ & $89 \pm 19$ & $52 \pm 10$ & $24,152 \pm 5038$ & $26 \pm 7$ & $46 \pm 12$ & $13 \pm 3$ & 76 & $40 \pm 8$ & 55 \\
\hline \multicolumn{12}{|l|}{$60 \mathrm{~min}$ recovery } \\
\hline AL cold $\left(4^{\circ} \mathrm{C}\right)$ & 8 & $303 \pm 14$ & $113 \pm 3$ & $59 \pm 1$ & $33,991 \pm 751$ & $42 \pm 3$ & $68 \pm 3$ & $18 \pm 1$ & 86 & $60 \pm 2$ & 72 \\
\hline Celsior $\left(4^{\circ} \mathrm{C}\right)$ & 6 & $267 \pm 10$ & $111 \pm 3$ & $64 \pm 2$ & $31,773 \pm 1010$ & $38 \pm 1$ & $63 \pm 3$ & $16 \pm 1$ & 80 & $54 \pm 1$ & 68 \\
\hline $\operatorname{AL}\left(29^{\circ} \mathrm{C}\right)$ & 8 & $285 \pm 15$ & $110 \pm 4$ & $60 \pm 0$ & $31,233 \pm 1451$ & $36 \pm 3$ & $75 \pm 3$ & $15 \pm 1$ & 94 & $51 \pm 3$ & 80 \\
\hline Plus 1-mmol/L Pyr & 8 & $287 \pm 14$ & $113 \pm 3$ & $65 \pm 3$ & $32,336 \pm 1629$ & $38 \pm 2$ & $83 \pm 3$ & $16 \pm 1$ & 100 & $53 \pm 2$ & 86 \\
\hline Plus 5-mmol/L Pyr & 8 & $256 \pm 9$ & $114 \pm 3$ & $59 \pm 1$ & $28,963 \pm 431$ & $39 \pm 3$ & $76 \pm 3$ & $15 \pm 1$ & 83 & $55 \pm 4$ & 79 \\
\hline Celsior $\left(29^{\circ} \mathrm{C}\right)$ & 6 & $230 \pm 47$ & $91 \pm 19$ & $51 \pm 10$ & $25,043 \pm 5167$ & $26 \pm 7$ & $46 \pm 12$ & $14 \pm 3$ & 82 & $41 \pm 9$ & 56 \\
\hline
\end{tabular}

Functional parameters of isolated working rat hearts before arrest and during 60 minutes of reperfusion after 2-hour arrest with adenosine-lidocaine cardioplegia or Celsior (Sangstat Medical Corp, Fremont, CA) during cold static storage $\left(4^{\circ} \mathrm{C}\right)$ and after cardioplegia with adenosine-lidocaine with $\mathrm{L}-$ pyruvate at 0,1 , or $5 \mathrm{mmol} / \mathrm{L}$ or with Celsior intermittently perfused every 20 minutes for 2 minutes at $68 \mathrm{~mm} \mathrm{Hg}$ and $37^{\circ} \mathrm{C}$ (average arrest temperature $28^{\circ} \mathrm{C}-30^{\circ} \mathrm{C}$; see Material and Methods section for details). $\% P A$, Percentage of prearrest value; $A L$, adenosine-lidocaine; $P y r$, L-pyruvate.

arrhythmias relative to those in the AL group as well (data not shown). Hearts in the AL group had returned to a significantly higher cardiac output (45\% higher) than had those in the Celsior group after 60 minutes of reperfusion after 6 hours of arrest (Figure 1, $A$ ).

\section{Warmer Arrest With Intermittent Flushes $\left(28^{\circ} \mathrm{C}-\right.$ $30^{\circ}$ C): Cardioplegic Volumes, CVRs, and Recoveries After 2 and 6 Hours of Arrest}

The total cardioplegic volumes for hearts with 0-, 1-, and 5mmol/L pyruvate delivered with AL cardioplegia during the 2-hour arrest period were $222 \pm 17,287 \pm 11$, and $313 \pm 15$ $\mathrm{mL}$, respectively; those with cardioplegia delivered during 6 hours were $519 \pm 33,509 \pm 39$, and $652 \pm 26 \mathrm{~mL}$. Hearts receiving $\mathrm{AL}$ supplemented with $5-\mathrm{mmol} / \mathrm{L}$ pyruvate had significantly higher total volumes infused than hearts receiving $\mathrm{AL}$ with either 0 - or $1-\mathrm{mmol} / \mathrm{L}$ pyruvate $(P=.014)$. The total cardioplegic volumes for hearts with Celsior delivered during 2 and 6 hours of arrest were $293 \pm 20 \mathrm{~mL}$ and 411 $\pm 53 \mathrm{~mL}$, respectively. Hearts receiving Celsior solution had $21 \%$ to $37 \%$ lower total volumes than did the AL groups, but these differences were not significantly different.

The values of CVR before cardioplegic arrest for hearts perfused with AL solution with 0-, 1-, and 5-mmol/L pyruvate and those perfused with Celsior were $0.32 \pm 0.02,0.35$ $\pm 0.01,0.33 \pm 0.01$, and $0.31 \pm 0.02 \mathrm{Mdyne} \cdot \mathrm{s} \cdot \mathrm{cm}^{-5}$, respectively (Figure 2). The prearrest CVRs were not significantly different. During 2 minutes of intermittent infusions, CVRs in the three AL groups increased by 1.3 times at 3 hours to 1.7 and 1.9 times at 6 hours (not significant, between AL groups). The CVR in the Celsior group increased 1.8 times $\left(0.56 \pm 0.08 \mathrm{Mdyne} \cdot \mathrm{s} \cdot \mathrm{cm}^{-5}\right)$ at 3 hours and 2.8 times $(0.86 \pm 0.17)$ at 6 hours. At 3 hours, the CVR values for the Celsior group were significantly higher than for AL with $5-\mathrm{mmol} / \mathrm{L}$ pyruvate $(0.56$ vs $0.36 \mathrm{Mdyne} \cdot \mathrm{s} \cdot$ $\mathrm{cm}^{-5}$ ) and AL solution alone (0.56 vs 0.42 Mdyne • $\mathrm{s} \cdot$ $\left.\mathrm{cm}^{-5} ; P=.027\right)$. Despite the Celsior group having $30 \%$ to $76 \%$ higher CVR at 6 hours than the AL groups, however, 
TABLE 2. Functional parameters: Six-hour arrest protocol

\begin{tabular}{|c|c|c|c|c|c|c|c|c|c|c|c|}
\hline \multirow[b]{2}{*}{ Treatment } & \multirow[b]{2}{*}{$\mathbf{n}$} & \multirow{2}{*}{$\begin{array}{l}\text { Heart rate } \\
\text { (beats/min) }\end{array}$} & \multicolumn{2}{|c|}{ Pressure $(\mathrm{mm} \mathrm{Hg})$} & \multirow{2}{*}{$\begin{array}{c}\text { Rate-pressure } \\
\text { product }(\mathrm{mm} \mathrm{Hg} / \mathrm{min})\end{array}$} & \multicolumn{2}{|c|}{$\begin{array}{c}\text { Aortic } \\
\text { flow }(\mathrm{mL} / \mathrm{min})\end{array}$} & \multicolumn{2}{|c|}{$\begin{array}{c}\text { Coronary } \\
\text { flow }(\mathrm{mL} / \mathrm{min})\end{array}$} & \multicolumn{2}{|c|}{$\begin{array}{c}\text { Cardiac } \\
\text { output }(\mathrm{mL} / \mathrm{min})\end{array}$} \\
\hline & & & Systolic & Diastolic & & Value & $\% \mathbf{P A}$ & Value & $\% \mathbf{P A}$ & Value & $\% \mathbf{P A}$ \\
\hline \multicolumn{12}{|l|}{$15 \mathrm{~min}$ before arrest } \\
\hline AL cold $\left(4^{\circ} \mathrm{C}\right)$ & 8 & $279 \pm 9$ & $123 \pm 3$ & $60 \pm 0$ & $34,296 \pm 895$ & $61 \pm 2$ & & $20 \pm 2$ & & $81 \pm 3$ & \\
\hline Celsior $\left(4^{\circ} \mathrm{C}\right)$ & 5 & $295 \pm 19$ & $121 \pm 4$ & $60 \pm 0$ & $35,529 \pm 1744$ & $54 \pm 4$ & & $22 \pm 2$ & & $76 \pm 5$ & \\
\hline $\operatorname{AL}\left(29^{\circ} \mathrm{C}\right)$ & 8 & $297 \pm 10$ & $124 \pm 3$ & $60 \pm 0$ & $36,989 \pm 1386$ & $48 \pm 2$ & & $17 \pm 1$ & & $65 \pm 3$ & \\
\hline Plus 1-mmol/L Pyr & 8 & $271 \pm 7$ & $122 \pm 2$ & $60 \pm 0$ & $33,253 \pm 1245$ & $50 \pm 3$ & & $16 \pm 1$ & & $65 \pm 4$ & \\
\hline Plus 5-mmol/L Pyr & 8 & $264 \pm 10$ & $120 \pm 0$ & $56 \pm 2$ & $31,695 \pm 1151$ & $49 \pm 2$ & & $17 \pm 1$ & & $65 \pm 2$ & \\
\hline Celsior $\left(29^{\circ} \mathrm{C}\right)$ & 6 & $259 \pm 5$ & $127 \pm 2$ & $60 \pm 0$ & $32,920 \pm 306$ & $54 \pm 1$ & & $18 \pm 1$ & & $72 \pm 1$ & \\
\hline \multicolumn{12}{|l|}{15 min recovery } \\
\hline $\mathrm{AL}$ cold $\left(4^{\circ} \mathrm{C}\right)$ & 8 & $253 \pm 14$ & $108 \pm 4^{*}$ & $63 \pm 2 *$ & $27,144 \pm 1653^{*}$ & $30 \pm 4 *$ & 49 & $15 \pm 1$ & 75 & $45 \pm 4^{*}$ & 55 \\
\hline Celsior $\left(4^{\circ} \mathrm{C}\right)$ & 6 & $189 \pm 46$ & $75 \pm 24$ & $44 \pm 12$ & $16,649 \pm 6141$ & $17 \pm 7$ & 32 & $10 \pm 3$ & 46 & $27 \pm 10$ & 36 \\
\hline $\operatorname{AL}\left(29^{\circ} \mathrm{C}\right)$ & 8 & $230 \pm 16$ & $111 \pm 2 *$ & $61 \pm 1 *$ & $25,548 \pm 1793$ & $19 \pm 3$ & 40 & $12 \pm 1$ & 71 & $31 \pm 4$ & 48 \\
\hline Plus 1-mmol/L Pyr & 8 & $256 \pm 10^{*}$ & $114 \pm 2 *$ & $65 \pm 3^{*}$ & $29,110 \pm 990^{*}$ & $26 \pm 2$ & 52 & $14 \pm 1$ & 88 & $41 \pm 3$ & 63 \\
\hline Plus 5-mmol/L Pyr & 8 & $238 \pm 7$ & $101 \pm 1^{*}$ & $60 \pm 0^{*}$ & $24,084 \pm 678$ & $15 \pm 2$ & 31 & $14 \pm 1$ & 82 & $29 \pm 2$ & 45 \\
\hline Celsior $\left(29^{\circ} \mathrm{C}\right)$ & 6 & $0 \pm 0 \dagger$ & $6 \pm 3 \dagger$ & $4 \pm 3 \dagger$ & $0 \pm 0 \dagger$ & $0 \pm 0 \dagger$ & $0 \dagger$ & $1 \pm 1 \dagger$ & $1 \dagger$ & $1 \pm 1 \dagger$ & $0 \dagger$ \\
\hline \multicolumn{12}{|l|}{$30 \mathrm{~min}$ recovery } \\
\hline AL cold $\left(4^{\circ} \mathrm{C}\right)$ & 6 & $289 \pm 13$ & $109 \pm 3$ & $61 \pm 1^{*}$ & $31,476 \pm 932$ & $39 \pm 3^{*}$ & 61 & $16 \pm 2 *$ & $80 *$ & $53 \pm 3^{*}$ & 65 \\
\hline Celsior $\left(4^{\circ} \mathrm{C}\right)$ & 6 & $237 \pm 47$ & $88 \pm 19$ & $56 \pm 12$ & $24,303 \pm 6080$ & $22 \pm 7$ & 41 & $12 \pm 2$ & 55 & $34 \pm 9$ & 45 \\
\hline $\operatorname{AL}\left(29^{\circ} \mathrm{C}\right)$ & 8 & $259 \pm 12$ & $111 \pm 3$ & $61 \pm 4^{*}$ & $28,615 \pm 1131$ & $21 \pm 2$ & 44 & $12 \pm 1$ & 71 & $33 \pm 3$ & 51 \\
\hline Plus 1-mmol/L Pyr & 8 & $269 \pm 13$ & $113 \pm 3^{*}$ & $63 \pm 2 *$ & $30,224 \pm 1043$ & $32 \pm 3$ & 64 & $13 \pm 1$ & 81 & $47 \pm 4$ & 72 \\
\hline Plus 5-mmol/L Pyr & 8 & $269 \pm 11$ & $103 \pm 2$ & $60 \pm 0^{*}$ & $27,579 \pm 1093$ & $24 \pm 3$ & 49 & $13 \pm 1$ & 77 & $37 \pm 3$ & 57 \\
\hline Celsior $\left(29^{\circ} \mathrm{C}\right)$ & 6 & $0.0 \pm 0.0 \dagger$ & $4 \pm 2 \dagger$ & $3 \pm 2 \dagger$ & $0 \pm 0 \dagger$ & $0 \pm 0 \dagger$ & $0 \dagger$ & $1 \pm 1 \dagger$ & $1 \dagger$ & $1 \pm 1 \dagger$ & $0 \dagger$ \\
\hline \multicolumn{12}{|l|}{60 min recovery } \\
\hline $\mathrm{AL}$ cold $\left(4^{\circ} \mathrm{C}\right)$ & 6 & $292 \pm 12$ & $111 \pm 3^{*}$ & $63 \pm 2 *$ & $32,392 \pm 837^{*}$ & $37 \pm 3^{*}$ & 64 & $16 \pm 2 *$ & 80 & $55 \pm 3^{*}$ & $68 *$ \\
\hline Celsior $\left(4^{\circ} \mathrm{C}\right)$ & 6 & $240 \pm 61$ & $84 \pm 19$ & $56 \pm 12$ & $22,257 \pm 6248$ & $25 \pm 7$ & 46 & $11 \pm 2$ & 50 & $36 \pm 10$ & 47 \\
\hline $\operatorname{AL}\left(29^{\circ} \mathrm{C}\right)$ & 8 & $281 \pm 11$ & $109 \pm 2 *$ & $65 \pm 2 *$ & $30,470 \pm 1085$ & $24 \pm 2$ & 50 & $13 \pm 1$ & 76 & $36 \pm 3$ & 55 \\
\hline Plus 1-mmol/L Pyr & 8 & $286 \pm 14$ & $113 \pm 3 *$ & $63 \pm 2^{*}$ & $32,060 \pm 982^{*}$ & $35 \pm 3$ & 70 & $13 \pm 1$ & 81 & $49 \pm 4$ & 75 \\
\hline Plus 5-mmol/L Pyr & 8 & $280 \pm 11$ & $101 \pm 1^{*}$ & $60 \pm 0^{*}$ & $28,353 \pm 1299$ & $24 \pm 3$ & 49 & $13 \pm 1$ & 76 & $37 \pm 4$ & 57 \\
\hline Celsior $\left(29^{\circ} \mathrm{C}\right)$ & 6 & $0 \pm 0 \dagger$ & $4 \pm 2 \dagger$ & $1 \pm 1 \dagger$ & $0 \pm 0 \dagger$ & $0 \pm 0 \dagger$ & $0 \dagger$ & $1 \pm 1 \dagger$ & $1 \dagger$ & $1 \pm 1 \dagger$ & 0 \\
\hline
\end{tabular}

Functional parameters of isolated working rat hearts before arrest and during 60 minutes of reperfusion after 6-hour arrest with adenosine-lidocaine cardioplegia or Celsior (Sangstat Medical Corp, Fremont, CA) during cold static storage $\left(4^{\circ} \mathrm{C}\right)$ and after cardioplegia with adenosine-lidocaine with $\mathrm{L}$-pyruvate at 0,1 , or $5 \mathrm{mmol} / \mathrm{L}$ or with Celsior intermittently perfused every 20 minutes for 2 minutes at $68 \mathrm{~mm} \mathrm{Hg}$ and $37^{\circ} \mathrm{C}$ (average arrest temperature $28^{\circ} \mathrm{C}-30^{\circ} \mathrm{C}$; see Material and Methods section for details). $\% P A$, Percentage of prearrest value; $A L$, adenosine-lidocaine; $P y r$, L-pyruvate. *Significant at $P<.05$ between adenosine-lidocaine treatment groups and Celsior group according to 1 -way analysis of variance at each time point. $\dagger$ Significant at $P<.001$ between adenosine-lidocaine treatment groups and Celsior group according to 1 -way analysis of variance at each time point.

the differences failed to reach statistical significance, in part because of the large SEs of the Celsior group (Figure 2).

Recovery of functional parameters in hearts arrested at warmer temperatures (heart arrest temperatures $28^{\circ} \mathrm{C}-$ $30^{\circ} \mathrm{C}$ ) for 2 and 6 hours are shown in Tables 1 and 2. After 2 hours of arrest with AL cardioplegia, recovery of prearrest heart rate was $106 \% \pm 5 \%$, that of prearrest aortic flow was $75 \% \pm 3 \%$, and that of prearrest coronary flow was $94 \% \pm$ $5 \%$ (Table 1 ). The addition of $1-\mathrm{mmol} / \mathrm{L}$ pyruvate increased recovery of prearrest aortic flow from $75 \% \pm 3 \%$ to $83 \% \pm$ $3 \%$; however, this was not significant. Similarly, the addition of $1-\mathrm{mmol}$ pyruvate led to no significant changes in heart rate $(106 \% \pm 4 \%)$ or coronary flow $(100 \% \pm 3 \%)$ recovery relative to $\mathrm{AL}$ alone (Table 1). The addition of 5-mmol pyruvate to AL led to decreases in heart rate, aortic flow, and coronary flow of around $10 \%$ to $14 \%$; however, these changes were not significantly different from AL supplemented with 0 - or $1-\mathrm{mmol} / \mathrm{L}$ pyruvate. Rate-pressure products for AL with 0-, 1-, and 5-mmol/L pyruvate were $90 \%$ to $99 \%$ of prearrest values and not significantly different from each other. Cardiac outputs with AL supplemented with $0-, 1-$, and $5-\mathrm{mmol} / \mathrm{L}$ pyruvate were $80 \% \pm 3 \%, 86 \%$ $\pm 2 \%$, and $79 \% \pm 3 \%$ of prearrest values at 60 minutes of reperfusion after 2 hours of arrest and not significantly different from each other. After 2 hours of arrest with Celsior cardioplegia, recovery of prearrest heart rate was $82 \%$, that of prearrest aortic flow was $26 \% \pm 7 \%$, and that of prearrest coronary flow was $82 \% \pm 18 \%$ (Table 1). Systolic and diastolic pressures were $74 \%$ and $85 \%$ of prearrest values, rate-pressure product was $73 \%$ of prearrest value, and cardiac output was $56 \%$ of prearrest value (Table 1 ). Even though all three groups of AL hearts had a $65 \%$ to $80 \%$ higher aortic flow and $40 \%$ to $65 \%$ higher cardiac output than the Celsior group, the differences were not significant, in part because of the higher SEs in the Celsior group after 2 hours of arrest at the warmer temperatures (Table 1). 

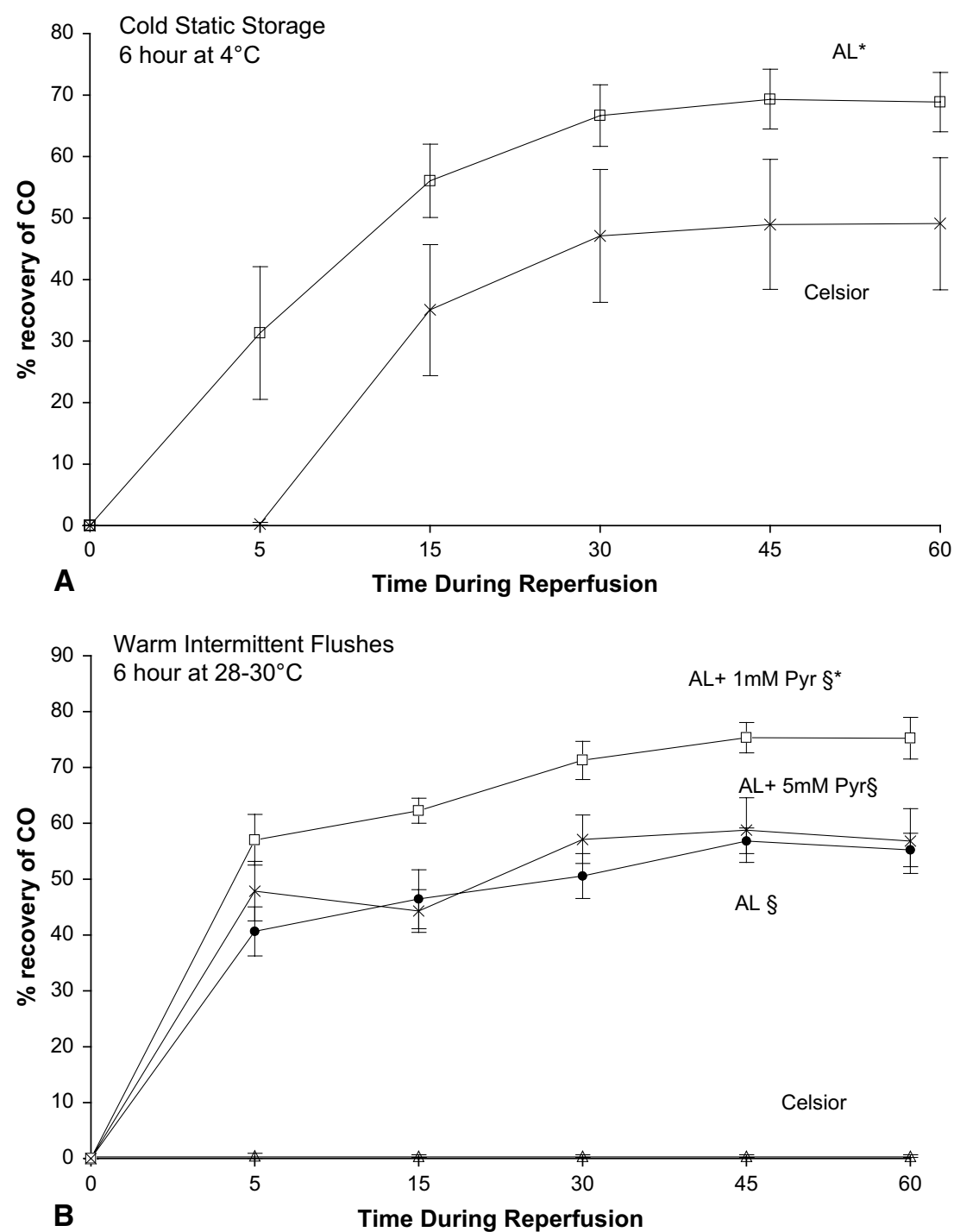

FIGURE 1. (A) Percentage recoveries of cardiac output during 60 minutes of reperfusion after 6 hours of cold $\left(4^{\circ} \mathrm{C}\right)$ static storage with adenosine-lidocaine $(A L)$ cardioplegia alone (squares) and with Celsior (crosses). Cardiac output is expressed as percentage of value 5 minutes before arrest. Values are mean \pm SEM. Asterisk indicates significant difference between adenosine-lidocaine and Celsior $(P<.05)$ by 2-way analysis of variance with repeated measures (see Materials and Methods section). (B) Percentage recoveries of cardiac output during 60 minutes of reperfusion after 6 hours of arrest at $28^{\circ} \mathrm{C}$ to $30^{\circ} \mathrm{C}$ with adenosine-lidocaine cardioplegia supplemented with 0-mmol/L L-pyruvate (Pyr, circles), 1-mmol/L L-pyruvate (squares), or 5-mmol/L L-pyruvate (crosses) or with Celsior (triangles). All adenosine-lidocaine groups had significantly higher cardiac output than Celsior group $(P<.0001)$. Asterisk indicates adenosine-lidocaine with 1 -mmol/L pyruvate preserved significantly higher cardiac output than with 0 - or 5 -mmol pyruvate $(P<.05)$ by 2 -way analysis of variance with repeated measures (see Materials and Methods section).

After 6 hours of intermittent cardioplegia and during 60 minutes of reperfusion, in hearts with AL alone recovery of prearrest heart rate was $95 \% \pm 3 \%$, recovery of prearrest aortic flow was $50 \% \pm 3 \%$, and recovery of prearrest coronary flow was $76 \% \pm 4 \%$ values (Table 2). The addition of 1 $\mathrm{mmol} / \mathrm{L}$ pyruvate to AL cardioplegia significantly increased recovery of aortic flow during the 60-minute reperfusion period $(P=.016)$; however, neither heart rate nor coronary flow was significantly changed (Table 2 ). The increase in aortic flow in the presence of $1-\mathrm{mmol} / \mathrm{L}$ pyruvate was apparent at all reperfusion times $(15,30,45$, and 60 minutes; Table 2$)$.
Cardiac output (aortic flow plus coronary flow) was also significantly higher in hearts with $\mathrm{AL}$ in the presence of 1 -mmol/L pyruvate $(49 \pm 4 \mathrm{~mL} / \mathrm{min})(P=.026)$ than in those with $\mathrm{AL}$ with $0-\mathrm{mmol} / \mathrm{L}$ pyruvate $(36 \pm 3 \mathrm{~mL} / \mathrm{min})$ or with 5 -mmol/L pyruvate $(37 \pm 4 \mathrm{~mL} / \mathrm{min}$; Figure $1, B)$. Rate-pressure products for hearts perfused with $\mathrm{AL}$ with $0-, 1-$, and 5 -mmol/L pyruvate were $82 \%, 96 \%$, and $90 \%$ of prearrest values and not significantly different from each other. Under identical 6-hour arrest conditions, hearts perfused with Celsior did not have return of a heart rate, developed pressures (4 $\mathrm{mm} \mathrm{Hg}$ ), and aortic and coronary flows and therefore had 


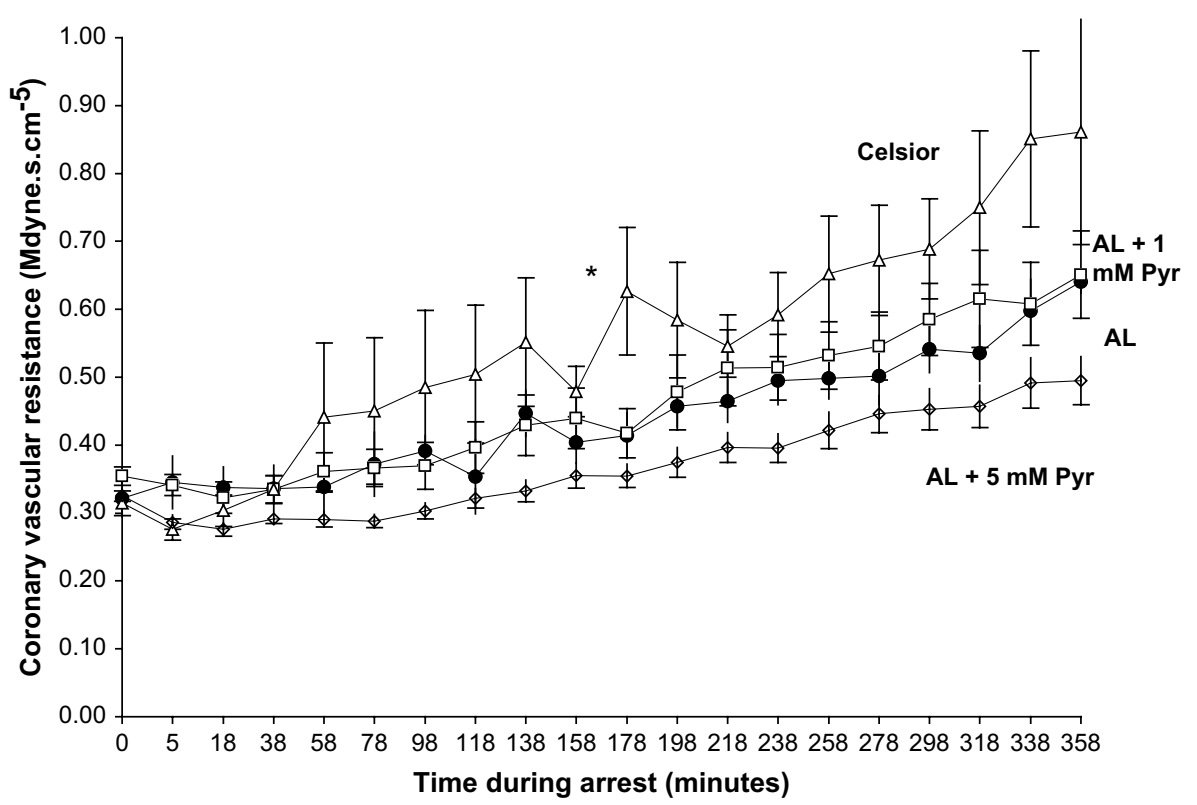

FIGURE 2. Coronary vascular resistance during 6 hours of arrest for adenosine-lidocaine $(A L)$ cardioplegia supplemented with 0 -mmol/L L-pyruvate $(P y r$, circles), 1-mmol/L L-pyruvate (squares), or 5-mmol/L L-pyruvate (diamonds) or with Celsior (Sangstat Medical Corp, Fremont, CA) (triangles). Coronary vascular resistance was calculated during 2-minute cardioplegia delivery every 18 minutes during total arrest time. Values are mean \pm SEM. For clarity, only 6-hour arrest data are presented. No significant differences were found between any group at baseline. There were no significant differences in first 2 hours between the 2-and 6-hour arrest protocols for all adenosine-lidocaine groups. Asterisk indicates at 178 minutes hearts treated with adenosine-lidocaine plus 5 -mmol/L pyruvate and with adenosine-lidocaine alone had significantly lower coronary vascular resistance than those treated with Celsior $(P<.05)$.

no cardiac output during the 60-minute reperfusion (Figure 1, $B$, Table 2). In direct contrast to the AL group, heart in the Celsior group were visibly small, hard, distorted, and discolored.

Values of total tissue water for AL-perfused hearts after 2 and 6 hours of cold static storage and 60 minutes reperfusion were $84 \% \pm 1 \%$ and $86 \% \pm 1 \%$, respectively. For hearts in the Celsior group, the total tissue water values were $82 \% \pm$ $2 \%$ and $84 \% \pm 1 \%$ for 2 and 6 hours of cold static storage, respectively. After warm intermittent arrest and 60 minutes of reperfusion, the total tissue water values were $87 \% \pm$ $1 \%, 88 \% \pm 1 \%$, and $87 \% \pm 1 \%$ for AL with $0-, 1-$, and 5 -mmol/L pyruvate, respectively (not significantly different). The total tissue water for hearts in the Celsior group was $84 \% \pm 4 \%$ and was not significantly different from the AL groups.

\section{DISCUSSION}

For more than 3 decades, protocols for heart retrieval and preservation solutions have relied almost exclusively on hyperkalemic depolarizing arrest, static storage, and profound hypothermia. ${ }^{1,3}$ Of the 167 different types of heart solution in the United States, ${ }^{22}$ no single solution has demonstrated consistent, clinically significant improvement relative to the others, including protection of the transplanted organ in the transition from cold to warm during poststorage implantation. ${ }^{2}$ In our quest to develop a new nondepolarizing, normokalemic transplant paradigm, we report that $\mathrm{AL}$ cardioplegia is versatile at both $4^{\circ} \mathrm{C}$ and at $28^{\circ} \mathrm{C}$ to $30^{\circ} \mathrm{C}$ for as long as 6 hours, and the addition of $1-\mathrm{mmol} / \mathrm{L}$ pyruvate to the warmer cardioplegia significantly improves recovery of cardiac output by $36 \%$. After arrest, AL-treated hearts with $1-\mathrm{mmol} / \mathrm{L}$ pyruvate added had spontaneously returned to $106 \%$ of prearrest heart rate, $93 \%$ to $105 \%$ of prearrest developed pressures, $70 \%$ of prearrest aortic flow, $81 \%$ of prearrest coronary flow, and $75 \%$ of prearrest cardiac output working against a pressure head of $76 \mathrm{~mm} \mathrm{Hg}(100 \mathrm{~cm}$ $\mathrm{H}_{2} \mathrm{O}$ ). In addition, the CVR in AL-treated hearts increased less than 2-fold during the 6-hour arrest period at the warmer arrest temperatures. Whereas hearts infused with AL cardioplegia showed functional equivalency with those infused with Celsior after 2 hours of cold and warm arrest, ALinfused hearts showed significantly improved outcomes after 6 hours. After 6 hours of intermittent delivery at $28^{\circ} \mathrm{C}$ to $30^{\circ} \mathrm{C}$, Celsior-infused hearts had no recovery of heart rate, developed pressures, and cardiac output, whereas the three AL groups had recovery of $55 \%$ to $75 \%$ of cardiac output.

\section{Cold Static Storage for 2 and 6 Hours $\left(4^{\circ} \mathrm{C}\right)$}

Currently, cold static storage is the most widely used form of preservation in heart transplant practice. ${ }^{3}$ In this study, we showed functional equivalence between AL cardioplegia and Celsior after 2 hours of static storage, with around $70 \%$ return of cardiac output (Table 1). After 6 hours of cold static storage, however, the AL group had significantly higher functional recovery values, with a $22 \%$ higher heart rate, $32 \%$ higher systolic pressures, a $46 \%$ higher rate-pressure product, a $48 \%$ 
higher aortic flow, a $45 \%$ higher coronary flow, and a $45 \%$ higher cardiac output (Table 2, Figure 1, $A$ ). A lower recovery in Celsior-treated hearts after 6 hours is in good agreement with the isolated working rat heart study of McDonald and colleagues, ${ }^{21}$ which showed a return of prearrest cardiac output of $22 \% \pm 9 \%$ ( $15 \%$ aortic flow and $31 \%$ coronary flow) at 30 minutes of reperfusion after 6 hours of static storage at $2^{\circ} \mathrm{C}$ to $3{ }^{\circ} \mathrm{C}$. McDonald and colleagues ${ }^{21}$ further reported that the cardiac output increased to about $70 \%$ with the addition of cariporide and glyceryl trinitrate to Celsior. Surprisingly there are few isolated working heart studies in the literature comparing Celsior with other preservation solutions, because most researchers prefer to use Langendorff hearts, which perform no physical work (adenosine triphosphate turnover with zero work, i.e. force times vertical distance). High heart rates and $90 \%$ to $100 \%$ returns of prearrest developed pressures in nonworking Langendorff mode may not necessarily translate to improved pump function. The working rat heart study of Nickless and associates ${ }^{23}$ showed approximately $80 \%$ recovery of prearrest cardiac output $(71 \%$ aortic flow and $93 \%$ coronary flow) after 5 hours of cold $\left(2^{\circ} \mathrm{C}\right)$ immersion in University of Wisconsin solution. Unfortunately, these workers did not report functional recovery data beyond $15 \mathrm{~min}$ utes of reperfusion, precluding a direct comparison with AL-infused hearts during 60 minutes of reperfusion.

Another important difference between our study and previous studies using Langendorff or working rat heart preparations is that we induced arrest at $37^{\circ} \mathrm{C}$, whereas others appear to have induced arrest at cold temperatures. ${ }^{21,23}$ To summarize, although functional recovery of AL-arrested hearts was superior to that of Celsior-arrested hearts after 6 hours of cold static storage, further studies are required to optimize the AL solution at these profoundly hypothermic temperatures. It is encouraging, however, that nondepolarizing, normokalemic AL in a physiologic, glucose-containing Krebs-Henseleit solution spontaneously returns good functional recoveries in the absence of an impermeant (eg, lactobionate, hydroxyethyl starch, mannitol) or a pharmacopeia of additives. Finally, another clinically relevant feature of AL cardioplegia, whether cold or warm, that deserves consideration is the spontaneous return of function without the need for defibrillation. ${ }^{17,24}$

\section{Intermittent Flushes at Warmer Arrest Temperatures $\left(28^{\circ} \mathrm{C}-30^{\circ} \mathrm{C}\right)$}

In this study, we showed that 2-minute top-ups after every 18 minutes of $\mathrm{AL}$ cardioplegia at $28^{\circ} \mathrm{C}$ to $30^{\circ} \mathrm{C}$ yielded spontaneous return of $80 \%$ of cardiac output after 2 hours and 55\% cardiac output after 6 hours (Tables 1 and 2). Further, when AL cardioplegia was supplemented with 1-mmol/ $\mathrm{L}$ pyruvate, the return of cardiac output increased from $55 \%$ to $75 \%$ after 60 minutes of reperfusion $(P=.026)$; Table 2$)$. Possible reasons that the addition of $1-\mathrm{mmol} / \mathrm{L}$ pyruvate improved aortic flow and cardiac output relative to 0 - or $5-\mathrm{mmol} / \mathrm{L}$ pyruvate is difficult to reconcile without meta- bolic analysis. It is known that pyruvate is a potent oxidizable fuel for heart tissue, and has been shown to decrease the cytosolic lactate/pyruvate ratio (lower the ratio of reduced to oxidized nicotinamine adenoside), enhance the cytosolic ratio of adenosine triphosphate to adenosine diphosphate and inorganic phosphate, improve contractility, suppress hydroxyl free-radical production, and reduce oxidative stress. ${ }^{25-27}$

In contrast, extracellular Celsior storage solution failed to protect the heart after 6 hours at $28^{\circ} \mathrm{C}$ to $30^{\circ} \mathrm{C}$ (Table 1), with no cardiac output during 60 minutes of reperfusion (Table 2 , Figure 1). Similarly, in 2004 we reported that St Thomas' Hospital solution performed poorly under identical conditions, with only $14 \%$ of hearts recovering function after 4 hours of arrest at $28^{\circ}$ to $30^{\circ} \mathrm{C} .{ }^{17} \mathrm{Ou}$ and colleagues ${ }^{28}$ further reported that University of Wisconsin solution is not protective at warmer temperatures and may even be deleterious. To be fair, Celsior (or, for that matter, University of Wisconsin solution) was not designed for warmer arrest and storage temperatures; it was originally designed as a perfusion fluid during initial donor arrest, poststorage graft implantation, and early reperfusion. ${ }^{20}$

\section{Static Cold Storage, Intermittent Flushes, or Continuous Perfusion?}

Controversy abounds in the literature regarding the optimal perfusion dynamics and ionic and metabolic composition for arrest, storage, and reanimation of human donor hearts. ${ }^{1,2}$ Commonly used preservation solutions for cold static storage are the University of Wisconsin, Celsior, Euro-Collins, and Bretschneider solutions. ${ }^{8}$ Although intermittent flush techniques similar to the method used in our study (or continuous low-pressure infusion delivery during cold storage) are not widely practiced today, their superiority has been experimentally demonstrated during the past 20 years, ${ }^{11,29}$ as reviewed by Nickless and associates ${ }^{23}$ and Jahania and colleagues. ${ }^{1}$ The major clinical objections to intermittent flush or continuous perfusion methods appear to be based largely on logistics, and not on efficacy, although myocardial extracellular edema and associated decreased ventricular compliance have been a concern with constant-infusion storage techniques. ${ }^{2,30}$ Some of these limitations have been partially solved by Hassanein and coworkers ${ }^{31}$ and others who have developed portable perfusion apparatus for use in donor human beating-heart preservation. The apparatus, which incorporates a low-pressure infusion of a warm, oxygenated nutrient solution to the human donor heart, is currently undergoing clinical trials in the United Kingdom and Germany.

\section{Possible Clinical Significance of the Normokalemic, Nondepolarizing AL Paradigm for Heart Transplant}

This study, which showed the versatility of cold and warmer AL in a crystalloid composition, may be directly relevant to all phases of heart transplant (donor harvest, storage, and implantation). The particular focus of our work 
on heart arrest, protection, and preservation is intended to reduce the negative impact of cold-to-warm wash and reperfusion temperatures, during which major damage to the adult or pediatric allograft often occurs. ${ }^{7,8,28}$ Currently, there is no preservation solution that can preserve the functional human heart safely beyond 4 to 5 hours.

The versatility of AL infusion as the primary arrest and reanimation strategy may be as follows: (1) AL induces rapid electromechanical arrest (as seen in this study and in references 2,17, and 24). (2) AL eliminates the need for high depolarizing potassium, which can lead to unnatural transmembrane voltages, ionic and metabolic imbalances, and electrical instability in myocytes, ${ }^{14,15}$ endothelial cells and vascular smooth muscle cells. ${ }^{12}$ High potassium is a potent vasoconstrictor and promotes vasospasm of the coronary arteries in diseased hearts. ${ }^{11}$ (3) Adenosine has the ability (through $\mathrm{A}_{1}$ receptor activation) to blunt the stimulatory effects of catecholamines, ${ }^{32}$ which may help to protect the heart during the harvest period. ${ }^{33}$ (4) AL maintains a lower CVR during prolonged storage (this study and references 17 and 24). (5) AL has antiarrhythmic properties that may be important to harvest, arrest, and reanimation $^{34,35}$ and to sinus nodal protection. (6) AL has been shown to preserve high-energy phosphates (adenosine triphosphate and phosphocreatine) during no- or low-flow ischemia. ${ }^{36}$ (7) Both adenosine and lidocaine have potent anti-inflammatory ${ }^{37}$ and anticoagulant properties, ${ }^{38}$ and may help to reduce acute and chronic rejection. (8) AL arrest led to a spontaneous return of improved left ventricular function against physiologic workloads after 6 hours of arrest, with recovery as great as $75 \%$ of prearrest cardiac output (this study and reference 17). (9) AL versatility permits the incorporation of warmer harvest, preservation, and reanimation temperatures, which may reduce the adverse effects of low perfusate temperatures on myocardial ischemia tolerance, rheology, and endothelial dysfunction and may reduce the incidence of arrhythmias. ${ }^{11}$ (10) Finally, AL solutions may help to rescue and stabilize the heart and other organs during harvest from beating-heart and nonbeating heart donors.

We to thank Professor Jakob Vinten Johansen for his continued scholarship and support for many years and throughout this study. The adenosine-lidocaine composition has been trademarked Adenocaine.

\section{References}

1. Jahania MS, Sanchez JA, Narayan P, Lasley RD, Mentzer RM Jr. Heart preservation for transplantation: principles and strategies. Ann Thorac Surg. 1999;68:1983-7.

2. Bethea BT, Yuh DD, Conte JV, Baumgartner WA. Heart transplantation. In: Cohn LH, Edmunds LH Jr., eds. Cardiac surgery in the adult. 2nd ed. New York: McGraw-Hill; 2003:1427-60.

3. Maathuis MH, Leuvenink HG, Ploeg RJ. Perspectives in organ preservation. Transplantation. 2007;83:1289-98.

4. Parolari A, Rubini P, Cannata A, Bonati L, Alamanni F, Tremoli E, et al. Endothelial damage during myocardial preservation and storage. Ann Thorac Surg. 2002;73: 682-90.

5. Young JB. Perspectives on cardiac allograft vasculopathy. Curr Atheroscler Rep. 2000;2:259-71.
6. Russo MJ, Chen JM, Sorabella RA, Martens TP, Garrido M, Davies RR, et al. The effect of ischemic time on survival after heart transplantation varies by donor age: an analysis of the United Network for Organ Sharing database. J Thorac Cardiovasc Surg. 2007; 133:554-9.

7. Stoica SC, Duwarakan K, Satchithananda K, Dunning J, Large SR. Two-decade analysis of cardiac storage for transplantation. Eur J Cardiothorac Surg. 2001;20: 792-8.

8. Ackemann J, Gross W, Mory M, Schaefer M, Gebhard M. Celsior versus custodiol: early postischemic recovery after cardioplegia and ischemia at $5^{\circ} \mathrm{C}$. Ann Thorac Surg. 2002;74:522-9.

9. Chambers DJ, Hearse DJ. Developments in cardioprotection: "polarized", arrest as an alternative to "depolarized" arrest. Ann Thorac Surg. 1999;68:1960-6.

10. Leicher FG, Magrassi P, LaRaia PJ, Derkac WM, Buckley MJ, Austen WG. Blood cardioplegia delivery. Deleterious effects of potassium versus lidocaine. Ann Surg. 1983;198:266-72.

11. Ozeki T, Kwon MH, Gu J, Collins MJ, Brassil J, Miller MB, et al. Heart preservation using continuous ex vivo perfusion improves viability and functional recovery. Circ J. 2007;71:153-9.

12. Ruel M, Khan TA, Voisine P, Bianchi C, Sellke FW. Vasomotor dysfunction after cardiac surgery. Eur J Cardiothorac Surg. 2004;26:1002-14.

13. Ellis RJ, Mavroudis C, Gardner C, Turley K, Ullyot D, Ebert PA. Relationship between atrioventricular arrhythmias and the concentration of $\mathrm{K}^{+}$ion in cardioplegic solution. J Thorac Cardiovasc Surg. 1980;80:517-26.

14. Spinale FG. Cellular and molecular therapeutics targets for treatment of contractile dysfunction after cardioplegic arrest. Ann Thorac Surg. 1999;68:1934-41.

15. Suleiman MS, Halestrap AP, Griffiths EJ. Mitochondria: a target for myocardial protection. Pharmacol Ther. 2001;89:29-46.

16. Chmiel B, Cierpka L. Organ preservation solutions impair deformability of erythrocytes in vitro. Transplant Proc. 2003;35:2163-4.

17. Dobson GP, Jones MW. Adenosine and lidocaine: a new concept in nondepolarizing surgical arrest, protection, and preservation. J Thoracic Cardiovasc Surg. 2004; 127:794-805.

18. Dobson GP. Organ arrest, protection and preservation: natural hibernation to cardiac surgery. Comp Biochem Physiol B Biochem Mol Biol. 2004;139:469-85.

19. Corvera JS, Kin H, Dobson GP, Kerendi F, Halkos ME, Katzmark S, et al. Polarized arrest with warm or cold adenosine/lidocaine blood cardioplegia is equivalent to hypothermic potassium blood cardioplegia. J Thorac Cardiovasc Surg. 2005; 129:599-606.

20. Menasché P, Termingnon JL, Pradier F, Grousset C, Mouas C, Alberici G, et al. Experimental evaluation of Celsior, a new heart preservation solution. Eur J Cardiothorac Surg. 1994;8:207-13.

21. Gao L, Hicks M, McDonald PS. Improved preservation of the rat heart with Celsior solution supplemented with cariporide plus glyceryl trinitrate. Am J Transplant. 2005;5:1820-6.

22. Demmy TL, Biddle JS, Bennett LE, Walls JT, Schmaltz RA, Curtis JJ. Organ preservation solutions in heart transplantation-patterns of usage and related survival. Transplantation. 1997;63:262-9.

23. Nickless DK, Rabinov M, Richards SM, Conyers RA, Rosenfeldt FL. Continuous perfusion improves preservation of donor rat hearts: importance of the implantation phase. Ann Thorac Surg. 1998;65:1265-72.

24. Sloots K, Vinten-Johansen J, Dobson GP. Warm nondepolarizing adenosine and lidocaine cardioplegia: continuous versus intermittent delivery. J Thorac Cardiovasc Surg. 2007;133:1171-8.

25. Dobsak P, Courderot-Masuyer C, Zeller M, Vergely C, Laubriet A, Assem M, et al. Antioxidative properties of pyruvate and protection of the ischemic rat heart during cardioplegia. J Cardiovasc Pharmacol. 1999;34:651-9.

26. Knott EM, Ryou MG, Sun J, Heymann A, Sharma AB, Lei Y, et al. Pyruvate-fortified cardioplegia suppresses oxidative stress and enhances phosphorylation potential of arrested myocardium. Am J Physiol Heart Circ Physiol. 2005;289: H1123-30.

27. Mallet RT. Metabolic cardioprotection by pyruvate: recent progress. Exp Biol Med. 2005;230:435-43.

28. Ou R, Gavin JB, Esmore DS, Rosenfeldt FL. Increased temperature reduces the protective effect of University of Wisconsin solution in the heart. Ann Thorac Surg. 1999;68:1628-34.

29. Wicomb WN, Hill DJ, Avery JG, Collins GM. Donor heart preservation-limitations of cardioplegia and warm ischemia. Transplantation. 1992;53:947-9.

30. Nameki T, Takeyoshi I, Oshima K, Kobayashi K, Sato H, Matsumoto K, et al. A comparative study of long-term heart preservation using 12-h continuous coronary perfusion versus 1 -h coronary perfusion following 11-h simple immersion. J Surg Res. 2006;135:107-12. 
31. Hassanein WH, Zellos L, Tyrrell TA, Healey NA, Crittenden MD, Birjiniuk V, et al. Continuous perfusion of donor hearts in the beating state extends preservation time and improves recovery of function. J Thorac Cardiovasc Surg. 1998;116:821-30.

32. Tikh EI, Fenton RA, Dobson JG. Contractile effects of adenosine A1 and A2A receptors in isolated murine hearts. Am J Physiol Heart Circ Physiol. 2006;290:H348-56.

33. Stoica SC, Satchithananda DK, White PA, Sharples L, Parameshwar J, Redington AN, et al. Brain death leads to abnormal contractile properties of the human donor right ventricle. J Thorac Cardiovasc Surg. 2006;132:116-23.

34. Canyon SJ, Dobson GP. Protection against ventricular arrhythmias and cardiac death using adenosine and lidocaine during regional ischemia in the in vivo rat. Am J Physiol Heart Circ Physiol. 2004;287:H1286-95.
35. Canyon SJ, Dobson GP. Pretreatment with an adenosine A1 receptor agonist and lidocaine: a possible alternative to myocardial preconditioning. J Thorac Cardiovasc Surg. 2005;130:371-7.

36. Canyon SJ, Dobson GP. The effect of adenosine and lidocaine infusion on myocardial high-energy phosphates and $\mathrm{pH}$ during regional ischemia in the rat model in vivo. Can J Physiol Pharmacol. 2006;84:903-12.

37. Hasko G, Cronstein BN. Adenosine: an endogenous regulator of innate immunity. Trends Immunol. 2004;25:33-9.

38. Deguchi H, Takeya H, Urano H, Gabazza EC, Zhou H, Suzuki K. Adenosine regulates tissue factor expression on endothelial cells. Thromb Res. 1998;91: 57-64. 